\title{
AS FACETAS DO CONVÍVIO COM O HIV: FORMAS DE RELAÇÕES SOCIAIS E REPRESENTAÇÕES SOCIAIS DA AIDS PARA PESSOAS SOROPOSITIVAS HOSPITALIZADAS
}

\author{
Las facetas del convivir con VIH/ SIDA: formas de relaciones sociales y representaciones \\ sociales del sida para personas seropositivas hospitalizadas
}

Facets of living with HIV: social relationships and social representations of aids to hospitalized soropositive people

Antonio Marcos Tosoli Gomes ${ }^{1}$

Caren Camargo do Espírito Santo ${ }^{4}$
Denize Cristina de Oliveira²

Bruno Rafael Gomes Valois ${ }^{5}$
Érick Igor dos Santos ${ }^{3}$

Ana Paula Munhen de Pontes ${ }^{6}$

\section{RESUMO}

0 objetivo deste estudo foi analisar as formas de relacionamentos sociais estabelecidos por pessoas hospitalizadas que vivem com HIV a partir das representações sociais que possuem acerca da AIDS. Utilizou-se a abordagem qualitativa, descritiva, baseada na Teoria das Representações Sociais. 0 cenário foi um hospital universitário situado no município do Rio de Janeiro. Participaram 13 sujeitos. Os dados foram coletados por meio de entrevistas em profundidade e analisados a partir da análise lexical utilizandose o software Alceste 4.7. 0 bloco temático analisado abarca as classes 2, 4 e 5. São evidenciadas formas de relação mantidas no contexto da exposição ao vírus, no contexto de cuidado prestado pela equipe de enfermagem, e, por fim, no contexto de enfrentamento da AIDS no relacionamento consigo e com o mundo. Conclui-se que os sujeitos do estudo parecem esquematizar suas multifacetárias relações interpessoais a partir de uma organização psicossociológica do HIV/AIDS.

Palavras-chave: Síndrome de imunodeficiência adquirida. Cuidados de enfermagem. Doenças sexualmente transmissíveis

\begin{abstract}
This study aimed to analyze social relationships made by hospitalized people who live with HIV under their social representations of AIDS. It was used a descriptive and qualitative approach based on the Social Representations Theory. Data was collected in a teaching hospital from Rio de Janeiro, where 13 people were interviewed. Data were collected through interviews and analyzed based on lexical analysis using Alceste 4.7 software. The analysis covers the thematic group classes 2, 4 and 5. Social relationships built at virus exposure situations, at nursing care process and at the sickness confront context are revealed, such as relationships kept within themselves and with the world too. It was concluded that the patients seem to diagram their complex relationships by a psychosocial organization of HIV/Aids.
\end{abstract}

Keywords: Acquired Immunodeficiency Syndrome. Nursing Care. Sexually Transmitted Diseases

\section{Resumen}

El objetivo de este estudio fue analizar las interfaces de las representaciones sociales con el cotidiano de las personas que conviven con VIH/Sida. El enfoque fue cualitativo, descriptivo, basado en la Teoría de las Representaciones Sociales. El escenario fue un hospital universitario en Rio de Janeiro. Participaron 13 sujetos. Los datos fueron recolectados por entrevistas y fue hecho el análisis léxico a través del software Alceste 4.7. El grupo temático analizado abarca las clases 2, 4 y 5 . Dimensiones afectivas fueron identificadas en las representaciones de los pacientes sobre los cuidados de enfermería. El preservativo es la imagen de la principal forma de prevenir el Sida. La principal forma de hacer frente a la enfermedad es la negación. Se concluye que la rutina de los pacientes ocurre en un campo lleno de tensiones pero la actitud frente a la terapia antirretroviral es positiva y los pacientes parecen sentirse parte del proceso de cuidado.

Palabras clave: Síndrome de Inmunodeficiencia Adquirida. Atención de Enfermería. Enfermedades de Transmisión Sexual

\footnotetext{
'Enfermeiro. Doutor em Enfermagem pela Escola de Enfermagem Anna Nery (UFR). Professor Adjunto da Faculdade de Enfermagem da Universidade do Estado do Rio de Janeiro (UERJ). Rio de Janeiro - RJ. Brasil. E-mail:mtosoli@gmail.com; Enfermeira. Doutora em Saúde Pública pela Universidade de São Paulo e PósDoutora em Psicologia Social pela École des Hautes Etudes en Sciences Sociales (EHESS), Paris/França. Professora Titular da Área de Pesquisa na Faculdade de Enfermagem (UERJ). Rio de Janeiro - RJ. Brasil. E-mail: dcouerj@gmail.com; ${ }^{3}$ Enfermeiro. Mestrando em Enfermagem pela Universidade do Estado do Rio de Janeiro. Professor da Fundação de Apoio à Escola Técnica do Estado do Rio de Janeiro. Rio de Janeiro - RJ. Brasil. E-mail: eiuerj@gmail.com; ${ }^{4}$ Enfermeira. Mestranda em Enfermagem pela Universidade do Estado do Rio de Janeiro. Bolsista da Coordenação de Aperfeiçoamento de Pessoal de Nível Superior. Rio de Janeiro - RJ. Brasil. E-mail: carencamargo.enf@gmail.com; ${ }^{5}$ Enfermeiro. Mestrando em Enfermagem pela Universidade do Estado do Rio de Janeiro. Enfermeiro da Polícia Militar do Rio de Janeiro. Rio de Janeiro - RJ. Brasil. E-mail: brunovalois@hotmail.com.br; ${ }^{6}$ Enfermeira. Mestre em Enfermagem pela Universidade do Estado do Rio de Janeiro. Enfermeira da Secretaria Municipal de Saúde de Duque de Caxias. Rio de Janeiro - RJ. Brasil. E-mail: anamunhen@gmail.com.
} 


\section{INTRODUÇÃO}

A AIDS é a primeira doença cujas histórias médica e social se desenvolveram de modo concomitante. A sociedade apoderou-se deste mal desconhecido e estranho, reconstruindo-o a partir de interfaces entre as concepções pertencentes a seu arsenal cultural e aquelas pertencentes à ciência, outrora tão incipientes. 0 que se sabia sobre a transmissão da doença e de suas vítimas favoreceu, em particular, a eclosão de duas concepções: uma do tipo moral e social, outra do tipo biológico, com a influência evidente de cada uma delas sobre os compor tamentos, nas relações íntimas ou para com as pessoas afetadas pela doença. A falta de informação e a incerteza da ciência favoreceram o surgimento de tais representações que circulavam entre as pessoas e/ou corriam de um veículo de comunicação a outro.'

No Brasil, a AIDS caracterizou-se desde o início dos anos 80 como um problema quase que exclusivo da área da saúde. Desta forma, a maior parte das políticas públicas emanava deste setor, que tem também executado quase a totalidade das ações programáticas de prevenção e de controle da epidemia. ${ }^{2}$ Neste sentido, três fases caracterizaram a expansão da epidemia, considerando a evolução histórica da AIDS no Brasil. A fase inicial focalizou apenas os infectados pelo HIV (Vírus da Imunodeficiência Adquirida), sendo marcada pelo conceito de "grupo de risco", que se restringia, basicamente, aos homens homossexuais, que possuíam alto nível de escolaridade. ${ }^{3}$ A segunda orientouse por uma perspectiva cujo centro era a exposição ao vírus. Percebeu-se que a maior forma de transmissão se dava via drogas injetáveis e atingia um número cada vez maior de heterossexuais. Adotou-se, então, o conceito de "comportamento de risco".

Outrossim, ante 0 aumento da infecção entre heterossexuais, 0 aumento da infecção entre a população feminina, a baixa escolaridade da população afetada e a interiorização da doença para municípios de médio e pequeno porte, urge a necessidade de ampliação do olhar sobre a AIDS. A terceira fase e atual, procura caracterizar a suscetibilidade dos indivíduos de maneira mais global à contaminação pelo HIV. Adota-se, então, o conceito de "vulnerabilidade". A importância da ideia de vulnerabilidade reside no reconhecimento de que a infecção pelo HIV não depende apenas da informaç̧ão e da postura individual, mas de uma série de fatores estruturais, tais como políticos, econômicos e culturais, que afetam os indivíduos, independente de sua vontade. ${ }^{3}$

Coadunando-se à perspectiva da vulnerabilidade, acredita-se que a Teoria das Representações Sociais seja pertinente à compreensão do univer so consensual da AIDSs em um determinado grupo em um determinado espaço-tempo, incluindo-se aí seus conhecimentos, práticas, simbolismos e relações mantidas intra e extragrupo em um cenário no qual a AIDS incide. Em outras palavras, estudos que perscrutam as representações sociais da AIDS possibilitam a apreensão de processos e mecanismos pelos quais os sujeitos constroem o sentido desta epidemia em suas realidades cotidianas 4 , por isso a sua importância.

Neste sentido, assume-se como objeto deste estudo as formas de relacionamentos que pessoas hospitalizadas que vivem com HIV/AIDS estabelecem e suas relações com as representações sociais que estas possuem acerca da própria síndrome. Destaca-se ainda que este estudo se configura como resultado preliminar de um projeto integrado que busca discutir o cuidado de enfermagem no contexto do HIV/AIDS. A justificativa deste estudo reside no aumento do número de casos novos de infecção por HIV no Brasil, em paralelo às constantes campanhas de prevenção da síndrome, o que torna necessário uma maior compreensão acerca do viver cotidiano dos portadores do vírus. Para tanto, traçou-se como objetivo deste estudo analisar as formas de relacionamentos sociais estabelecidos por pessoas hospitalizadas que vivem com HIV a partir das representações sociais que estes possuem acerca da AIDS.

\section{REVISÃO DE LITERATURA}

Por sua paradigmática e repercussões multifacetárias, foram encontrados diversos estudos cujo objeto estava relacionado à AIDS e ao seu representar social. Estes se mostram bastante heterogêneos, sobremaneira quanto a seus desenhos metodológicos e resultados encontrados. Variaram, também, os campos do conhecimento que dedicaram esforços para o esmiuçar dos processos simbólicos da AIDS, destacando-se aí o campo da Enfermagem. Por isso, a literatura, então, foi exaustivamente explorada, com subsequente seleção daqueles documentos aderentes aos dados obtidos neste estudo para sua posterior discussão. Foi respeitado o limite máximo de citações bibliográficas delimitado pelo periódico em questão.

Entre diversos outros, pode-se evidenciar estudos que apontam a Teoria das Representações Sociais como arsenal teórico e metodológico executável à análise em nível psicossocial, ${ }^{4}$ que descortinem as expectativas de pacientes soropositivos acerca do cuidado de enfermagem ${ }^{5}$ e que investiguem a manifestação clínica e psicossociológica da AIDS na criança ${ }^{6}$, no adolescente ${ }^{7}$ e em seu contexto familiar, e o modo de viver e de se relacionar de pessoas soropositivas após o advento da terapia antirretrovira ${ }^{8-9}$, e que proponham novos caminhos rumo à integralidade da atenção ao portador do HIV/ AIDS. ${ }^{10}$ 


\section{MÉTODO}

Trata-se de um estudo de abordagem qualitativa, descritivo, baseado na Teoria das Representações Sociais na perspectiva da Psicologia Social. Esta teoria é considerada como uma ciência coletiva sui generis e apresenta-se como um sistema de interpretação da realidade que guia as relações dos indivíduos com o seu meio físico e social. ${ }^{11}$ Uma representação social é entendida como "uma forma de conhecimento socialmente elaborada e partilhada, tendo uma orientação prática e concorrendo para a construção de uma realidade comum a um conjunto social" 2:22

Como cenário do estudo, foi escolhido um hospital universitário da rede pública de saúde, situado no município do Rio de Janeiro. Participaram da pesquisa 13 pessoas que vivem com HIV, internadas na enfermaria de Doenças Infecto-Contagiosas (DIP) e nas enfermarias de clínica médica do hospital supracitado. Foram incluídos os pacientes com o tempo de diagnóstico superior a um ano pela relevância do fator tempo no forjar de representaç̃̃es sociais. Foram excluídos os pacientes que possuíam algum grau de deficiência mental ou física que impossibilitaria a execução da entrevista. Os sujeitos tinham, em sua maioria, idade maior que 40 anos, pertenciam ao sexo masculino, professavam a religião católica, eram casados, tinham relacionamento estável e possuíam o ensino fundamental completo.

Os dados foram coletados em 2009 por meio de entrevistas em profundidade orientadas por um roteiro temático, que foi constituído por quatro blocos temáticos, quais sejam, as representações e memórias da AIDS, as representações e memórias do cuidado de enfermagem, o processo de adesão à terapia e os aspectos políticos e programáticos da assistência. Os dados foram coletados em um ambiente isolado e calmo destinado à realização de exames diagnósticos e procedimentos terapêuticos. Foram analisados a partir de uma análise lexical utilizando-se o software Alceste 4.7 (Análise Lexical por Contexto de um Conjunto de Segmentos de Texto), que recorre a co-ocorrências das palavras contidas na discursividade dos entrevistados, organizando as informações que considera mais relevantes, dividindo-as em classes de acordo com as relações existentes entre as mesmas.

0 Alceste é um software desenvolvido na França em 1979 por Max Reinert e tem a finalidade de realizar, automaticamente, a análise lexical de conteúdo por meio de técnicas quantitativas de tratamento de dados textuais. Essa técnica, além de descrever as leis de distribuição do vocabulário, permite o estudo dos tipos de representação presentes no texto, em que os processos de constituição da representação social podem participar da interpretação das classes e da identificação das representações através da busca de elementos que indiquem a ancoragem e a objetivação nas classes resultantes da análise Alceste. ${ }^{12}$

Para garantir os aspectos éticos envolvidos no processo de desenvolvimento de uma pesquisa dentro de uma instituição, obedeceu-se a Resolução 196/96 do Ministério da Saúde, sendo esta pesquisa aprovada pelo Comitê de Ética em Pesquisa do Hospital Universitário Pedro Ernesto da Universidade do Estado do Rio de Janeiro, com número do protocolo de aprovação 200/08. Os sujeitos que concordaram em conceder a entrevista assinaram o Termo de Consentimento Livre e Esclarecido, como pré-requisito para a sua realização.

\section{RESULTADOS E DISCUSSÃO}

A estatística apontada pelo software Alceste 4.7 identificou 13 unidades de contextos iniciais (UCI). Cada uma destas unidades corresponde a uma entrevista, totalizando, portanto, 13 entrevistas. 0 corpus foi dividido em 1861 unidades de contexto elementares (UCE), que é a menor unidade de análise constituída por 3 ou 4 linhas de texto, significando $100 \%$ do material submetido à análise. 0 software classificou então, para análise final, 1291 UCE, que representam 67,37\% de aproveitamento do material submetido à análise.

As 1291 UCE foram agrupadas em um total de seis classes lexicais, o que caracteriza o conteúdo essencial presente nas entrevistas analisadas. Essas classes foram divididas em dois blocos temáticos, ilustrados pela Figura 1, que corresponde à classificação hierárquica descendente (dendograma) originada da análise realizada pelo software. Nesta figura, pode-se observar os processos de divisão e subdivisão realizados pelo Alceste 4.7, nos quais 0 corpus foi, em um primeiro momento, dividido em dois blocos temáticos de acordo com seus significados e, posteriormente, estes blocos temáticos foram redivididos em classes 1, 3, 6, 2, 4 e 5. Cabe ressaltar que a disposição das classes não foi realizada de maneira aleatória pelo software, que se incumbe de aproximá-las umas das outras de acordo com sua afinidade temática.

Para fins deste trabalho, serão analisadas as classes 2, 4 e 5, as quais compõem o bloco temático 2 , intitulado "Sentimentos, prevenção e empoderamento: as facetas do conviver com HIV/ AIDS". 


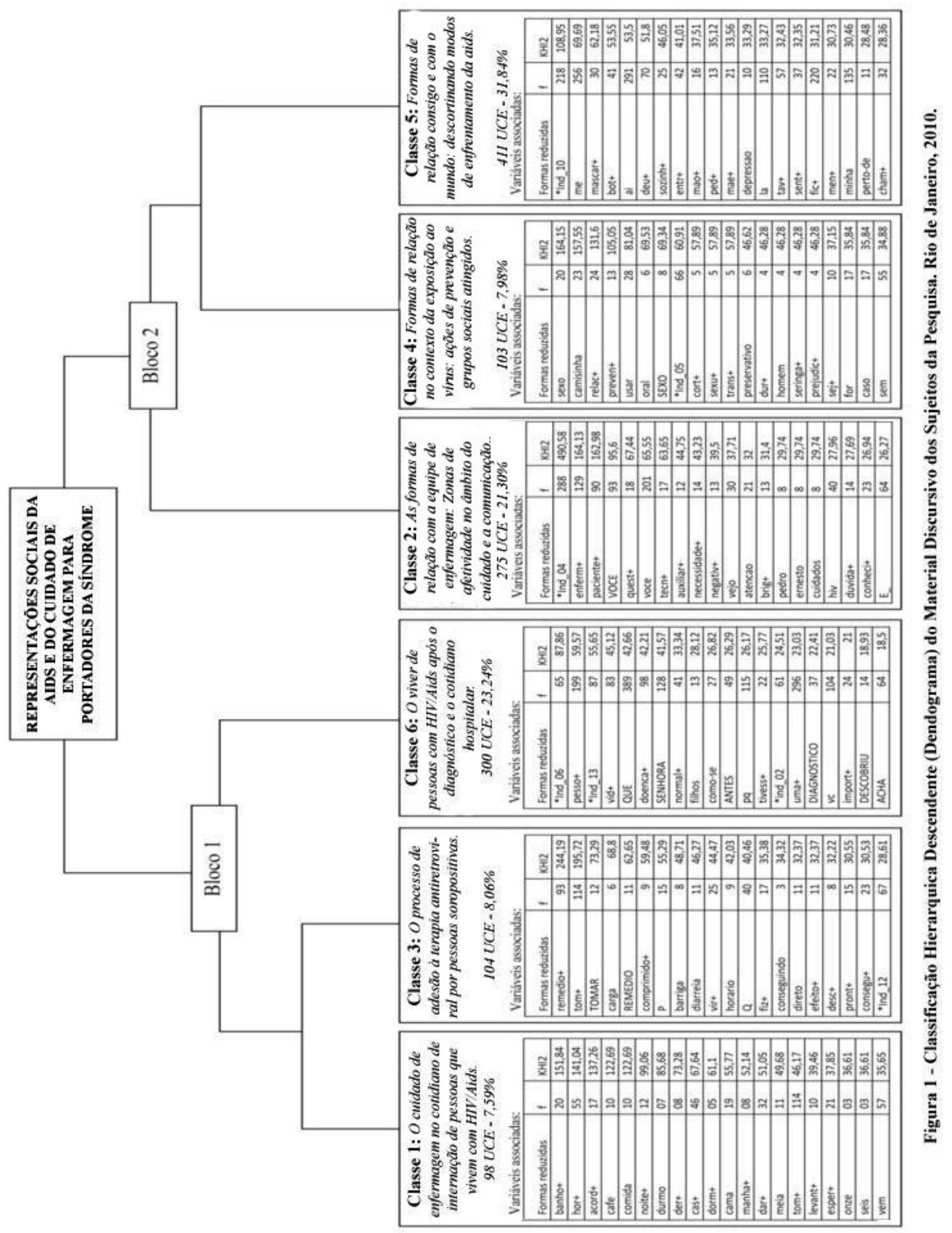




\section{Classe 2 - As formas de relação com a equipe de enfermagem: Zonas de afetividade no âmbito do cuidado e a presença da comunicação no trabalho em equipe}

Essa classe representa 21,30\% das UCE analisadas. Observa-se que as formas reduzidas de maior qui-quadrado $\left(x^{2}\right)$ são: Enferm + $\left(x^{2}=164.13\right)$, Paciente+ $\left(x^{2}=162.98\right)$, Tecn+ $\left(x^{2}=63.65\right)$, Auxiliar+ $\left(x^{2}=44.75\right)$, Necessidad $\left(x^{2}=43,23\right)$, Brig $+\left(x^{2}=31.14\right)$, Conheci+ $\left(x^{2}=26.94\right)$, Direitos $\left(x^{2}=24.24\right)$, Equip+ $\left(x^{2}=24.7\right)$, Preconceito $+\left(x^{2}=24.24\right)$, Dedic + $\left(x^{2}=21.04\right)$, Lut+ $\left(x^{2}=20.15\right)$, Codigo $\left(x^{2}=18.54\right)$ e Descaso $\left(x^{2}=18.54\right)$. As variáveis de maior associação à classe foram a idade acima de 40 anos e a presença de relacionamento estável. Através das palavras acima, observa-se a existência de um campo de tensões; as palavras brig + e lut+, por exemplo, revelam que conflitos são pontuados no contexto dos cuidados de enfermagem. Já as palavras "código" e "direitos" sugerem recursos legais dos pacientes para enfrentamento de possíveis preconceitos por parte da equipe, ao passo que são revelados aspectos positivos enegativos do cuidado de enfermagem através das palavras conheci+, dedic+ e descaso. É possível perceber que os profissionais que exercem este tipo de cuidado são diferentes uns dos outros e que é reconhecido seu trabalho em equipe, características notáveis através das palavras equip + , enferm+, tecn+e auxiliar+.

Em um cotidiano marcado pela presença da equipe de enfermagem, dimensões afetivas são identificáveis nas representações dos pacientes relacionadas aos cuidados de enfermagem, apontando-os como ponte entre o profissional e 0 paciente em um processo de envolvimento mútuo:

É enfermeiro com paciente. É o que eu te falei, a gente acaba formando um laço de amizade, então isso envolve até os pacientes. (E 2)

É provável que este envolvimento afetivo, explícito nas representações, seja oriundo não apenas da maior e mais constante proximidade do profissional de enfermagem aos pacientes, quando comparado com outros profissionais, mas também pelas dimensões éticas e estéticas da profissão, assim como por seus alicerces filosóficos e doutrinários. 0 afeto encontra lugar na interação entre os sujeitos cuidadores (de si e do outro), na qual a intersubjetividade se manifesta no cuidado. Desta forma, os pacientes portadores de HIV/AIDS reconhecem e legitimam a afetividade presente durante a atuação da enfermagem. 0 cuidado amoroso e a humanização caminham juntos, de forma a tornar possível a oferta assistencial que atenda às necessidades humanas destes indivíduos, respeitando sua dignidade, diminuindo o sofrimento e facilitando o alcance de seu projeto vital. $^{13}$

Em contraponto, alguns entrevistados atribuem falta de informação e de atenção aos cuidados de enfermagem, embora não culpabilizem o profissional individualmente, generalizando, assim, a característica de conhecimento insuficiente derivado da deficiência no processo de formação profissional. Em adição a isto, os sujeitos traçam um paradoxo entre teoria e prática.

São observáveis construções simbólicas que são atribuídas aos profissionais como consequência do relacionamento que se estabeleceu entre ambos.

Como eu te falei, eles olham para você e eles não te veem, vê o HIV, a AIDS. É um bichinho ambulante, um aidético ambulante, tá? E quando eu digo assim, falta de informação deles, também é questão de você procurar saber como cuidar ou não passam corretamente o que se aprende [na teoria] dentro das necessidades. (E 4)

Os dados empíricos revelam a existência de uma zona de simbolização relacionada à identidade vivenciada pelos pacientes em seu cotidiano. A objetivação deste preconceito toma o lugar, inclusive, do próprio sujeito, em um processo em que este é substituído pela patologia, de for te expressão negativa em suas dimensões social, cultural e imaginária. Estes dados implicam uma reflexão de duplo caminho. Se o preconceito faz parte das representações sociais da AIDS forjadas no contexto do cenário deste estudo, existem, aparentemente duas possibilidades não excludentes entre si: a necessidade iminente do resgate do cuidado na práxis dos profissionais, cabendo à enfermagem tomar posicionamento ativo nas políticas voltadas para os avanços no cuidado à saúde e na promoção do viver mais saudável;' ou um quadro de constante aumento das necessidades psicoafetivas dos pacientes, considerando os desgastes proporcionados pela infecção e pelo tratamento. Os pacientes sentem necessidadese tem expectativas voltadas para um acolhimento intenso e uma assistência mais individualizada ${ }^{5}$, assim como apresentam alta sensibilidade ao seu contexto. Ambas as possibilidades requerem intervenções de enfermagem, principalmente do enfermeiro enquanto líder da equipe, pois é evidenciada a necessidade de humanização, de respeito, de compreensão e de diálogo no cotidiano da atitude ética profissional de enfermagem, que constitui um resgate da vida, do humano e dos derives ecológicos. ${ }^{14}$ Implica a coesão de saberes técnicocientíicos aos teórico-metodológicos e à empatia.

Os sujeitos se referem, também, ao cuidado prestado em equipe. Mesmo não tendo sido destacada qualquer forma de hierarquização, a prática dos seus integrantes parece se configurar como interdependente. É reconhecido o papel integrante do paciente nos cuidados prestados por esta equipe, o que mostra a participação efetiva deste em seu assistir:

É uma equipe que trabalha em conjunto. 0 médico, enfermeiro, enfermagem, técnicos, por quenenhum deles, um não funciona sem o outro, entende? $E$ consequentemente, essa parceria, entre todos, aos médicos, ao enfermeiro, aos técnicos, essa parceria entre eles todos, e mais o paciente, é de suma importância, então isso tudo fica muito latente. (E 13) 
0 trabalho multidisciplinar no contexto hospitalar, quando realizado, possibilita múltiplos olhares e diferentes abordagens às demandas do paciente portador de HIV/AIDS. Representa uma das forças motrizes rumo à efetividade da terapêutica. Portanto, é imprescindível a desconstrução de centralidades hegemônicas e fragmentações do todo. É importante proporcionar ao indivíduo soropositivo para o HIV/AIDS as condições para participação ativa no gerenciamento do seu cuidar, posto que o cuidado é concebido, planejado e organizado a partir do paciente e a ele é dirigido. A escuta e 0 acolhimento, no plano do cuidado, encontram caminhos na assistência a partir de verdadeira comunicação entre usuários e profissionais. Desta forma, nem os profissionais podem limitarse à compreensão do dito - dispensando, aí, o não-dito - e serem limitados às suas competências técnicas, nem os usuários podem ser reduzidos a meros objetos dos detentores do saber absoluto, 0 que conferiria inautenticidade no encontro de cuidado ${ }^{15}$, haja vista a impermeabilidade à expressividade neste caso.

\section{Classe 4 - Formas de relação no contexto da exposição ao vírus: ações de prevenção e grupos sociais atingidos}

Esta classe representa 7,98\% das UCE analisadas. As palavras lexicais que apresentam maior qui-quadrado $\left(x^{2}\right)$ desta classe e que, portanto, a caracterizam são: sexo $\left(x^{2}\right.$ $164,15)$, camisinha $\left(x^{2} 157,55\right)$, relac $+\left(x^{2} 131,6\right)$, preven+ $\left(x^{2} 105,05\right)$, usar $\left(x^{2} 81,04\right)$, oral $\left(x^{2} 69,53\right)$, cort $+\left(x^{2}\right.$ $57,89)$, sexu+ $\left(x^{2} 57,89\right)$, trans $+\left(x^{2} 57,89\right)$, preservativ + $\left(x^{2} 46,62\right)$, dur+ $\left(x^{2} 46,28\right)$, homem $\left(x^{2} 46,28\right)$, seringa $+\left(x^{2}\right.$ $46,28)$, prejudic+ $\left(x^{2} 46,28\right)$, sej+ $\left(x^{2} 37,15\right)$, sem $\left(x^{2} 34,88\right)$, adquir+ $\left(x^{2} 34,68\right)$, comunicact $\left(x^{2} 34,68\right)$, drog $+\left(x^{2}\right.$ $32,77)$, namor+ ( $\left.x^{2} 32,59\right)$, beij+ $\left(x^{2} 29,13\right)$ e beb $+\left(x^{2}\right.$ $28,24)$. A única variável associada à esta classe foi o ensino médio completo.

Os sujeitos, ao se referirem às formas de prevenção da AIDS, relatam imageticamente a camisinha como principal forma de prevenção e ainda revelam orientações referentes ao seu uso, tais como não utilizá-la em mais de uma relação sexual, enquanto o uso do preservativo aparece como auto e heterocuidado.

Como todo ser humano, prevenção é você nas suas relações usar camisinha, nunca transe com a camisinha duas vezes porque isso infecta a outra pessoa que está ao seu lado[...] Então se você não pensa na saúde dos outros, você não está pensando na sua (E 3).

Ehoje não, hoje eu penso muito em mim, penso nas pessoas em não passar, em não transmitir. Acho que nem tem o que pensar, isso é um direito, um dever meu (E 4).

Foi observado, também, que as pessoas reconhecem o preservativo como um elemento importante para os relacionamentos extraconjugais. Ou seja, quando não se conhece a pessoa com a qual se relaciona, existe a representação de um "outro" que seja mais perigoso do que aquelas pessoas mais próximas. Este "outro" induz muitas vezes a uma prevenção simbólica, pois enquanto se preocupam com as outras pessoas, fazem um isolamento mesmo que inconsciente, quanto ao risco de contrair o HIV. ${ }^{16}$

Ainda em relação à prevenção, quando questionados quanto às fontes de informação as quais utilizam para tomar ciência acerca da doença, a mídia aparece com destaque, especialmente a televisão, como sendo uma das principais fontes de transmissão de conhecimento acerca da sua prevenção. Destacase ainda que, para os entrevistados, a imagem da camisinha como principal forma de prevenção da AIDS é reiterada pela mídia. Esta ainda aparece como fonte de informação em se tratando de conhecimentos e atualizações gerais da doença, com ênfase ao seu perfil epidemiológico.

Escuto muito essas ideias pela televisão; assim, tem que usar camisinha para evitar a doença, a gente tem que se prevenir, tem que usar camisinha (E 1).

Eultimamente agora, foram os idosos que acabaram batendo um recorde, que andaram pegando AIDS, sem usar camisinha. Aí estava dando uma reportagem dizendo sobre isto (E 10).

Destaca-se um papel central da mídia para a construção de uma imagem da AIDS relacionada ao cantor Cazuza, que apareceu quando se questionou sobre as pessoas importantes que, àépoca do surgimento da doença, foram veiculadas pela mídia.

Na época o que escuteifoi o Cazuza, depois não soube de mais nada (E 5).

Cazuza foi uma das primeiras figuras públicas a admitir, em 1989, que era soropositivo e falar abertamente sobre sua vida sexual. Na ocasião do diagnóstico, pesava 68 quilos e, em pouco tempo, chegou a 40 , sendo o seu falecimento em julho de 1990. A imagem do Cazuza no Brasil marcou de forma indelével a AIDS, e, anos após a sua morte, ele ainda é lembrado pela sociedade, como um símbolo da síndrome. Vale ressaltar, portanto, a importância dos meios de comunicação para o conhecimento, a difusão e a construção das representações sociais da AIDS. Essa importância se dá por dois aspectos: a imprensa anunciou 0 aparecimento de um novo fenômeno no campo da patologia e operou a passagem das informações sobre a doença no domínio médico e científico para a sociedade. Ao mesmo tempo, em sua especificidade, a AIDS deixou de ser tratada como um problema setorial, passando a haver o esclarecimento dos mecanismos fundamentais do funcionamento social. A noção do fenômeno social AIDS remete, assim, à maneira pela qual a mídia identifica e classifica os acontecimentos aos quais se refere. ${ }^{17}$

Em segundo lugar, a imprensa fez com que a AIDS 
circulasse entre diversos grupos sociais que, paulatinamente, se consideraram afetados e se mobilizaram, polarizando as relações que surgiam a seu respeito. Através dela, a doença tornou-se objeto de tomadas de posição e de enfrentamentos. Assim, a opinião representou constantemente um papel no cenário da AIDS. ${ }^{17}$

As formas de transmissão da AIDS referidas pelos sujeitos configuram-se em torno de duas situações: o sexo desprotegido, abarcando os sexos oral, vaginal e anal, e a utilização de drogas, com compartilhamento de seringas e utilização de canudos para aspiração de drogas, como a cocaína. Percebe-se, entretanto, que o sexo sem preservativo é mais enfatizado como o modo de transmissão da doença. Sendo assim, nota-se que os sujeitos demonstraram algum conhecimento quanto aos motivos que levam as pessoas a se contaminarem pelo vírus. No conjunto das respostas foram pontuados vários meios de transmissão, conceitos elaborados que compõem o universo reificado, ou seja, o conhecimento de natureza científica.

Fazendo sexo. Fazendo sexo oral ou vaginal ou anal (E 7).

A única forma de a pessoa se contaminar é realmente tendo relação, tendo sangramento, entende, ou utilizando drogas, ou até mesmo o canudo que a pessoa utiliza, por conta do sangramento no nariz (E 13).

Os entrevistados demonstram incertezas quanto a algumas práticas que podem ou não levar à infecção do HIV. 0 beijo na boca, por exemplo, para uns não transmite o vírus, enquanto que para outros isto não está muito claro. Existem dúvidas, também, quanto aos tipos de sexo que podem contaminá-los. Outras formas que surgiram foram se cortar e segurar na outra pessoa, o que caracteriza um pensamento difuso acerca da presença de machucados.

Osmodos desepegar AIDSéum corte, se cortare segurar na pessoa, eu acho que transmite, e beijo na boca, um tipo de sexo que a mulher e o homem se faz (E5).

A AIDS só se pega se eu der um corte, que aí no sangue da pessoa (...), se, no caso, eu pegar a unha e machucar com força, bem machucado. Na saliva eu acho que não pega (E 10).

Pelo sexo, aítem a segunda que é pelo oral, né, não deixa de ser né. Que mais que tem? Eu já não sei, eu tô perdido (E 7)

Uma questão que vale ser ressaltada é a vulnerabilidade, principalmente da mulher, para se contaminar com o HIV. A vulnerabilidade também é expressa no que tange ao relacionamento fixo, que é tido como uma forma de prevenção, ou seja, tem-se a ideia de que a relação estável, baseada na confiança e fidelidade, é fator de proteção contra a infecção do vírus. Outro ponto destacado é a questão de "fazer o que não se deve", exemplificado na relação extraconjugal, como um modo de infecção que se traduz, também, em vulnerabilidade para o(a) companheiro(a).

É, isso sempre acontece, mesmo que a mulher não queira, ela acaba cedendo e depois acaba gostando, se acostumando e fazendo tudo que o sexo traz com seu companheiro e similares (E 5).

[...] e às vezes eles acham que porque estão namorando, assim, tem esse caso né, porque arrumou uma namorada fixa [...] (E 8).

Pelas relações com as pessoas, com homem ou com mulher, sem preservativo, vocênão sabe o que estáfazendo [...]. que também é errado fazer isso, arriscar a vida da sua esposa fazendo coisa que não deve (E9).

Considera-se que a vulnerabilidade corresponde à chance de exposição das pessoas ao HIV e ao adoecimento pela AIDS não somente como resultante de um conjunto de aspectos individuais, mas também coletivos e contextuais. A vulnerabilidade tem três dimensões, quais sejam, a individual, a social e a programática. A dimensão individual parte da premissa de que todas as pessoas são suscetíveis à infecção pelo o HIV. Contudo, são levados em consideração os aspectos próprios ao modo de vida dos indivíduos que contribuam para que se exponham ao vírus ou proteger-se dele. ${ }^{18}$

A dimensão social da vulnerabilidade está relacionada aos fatores contextuais que definem e constrangem a vulnerabilidade individual. Tal como a estrutura jurídico-política e as diretrizes governamentais, as diferenças relacionadas ao gênero, às relações raciais, às relações entre gerações, às atitudes diante da sexualidade, da religião, da pobreza e da cultura são alguns aspectos que possibilitam uma maior compreensão dos comportamentos e práticas que se relacionam à exposição dos indivíduos ao HIV. E, por fim, a dimensão programática da vulnerabilidade busca avaliar como em circunstâncias sociais citadas, as instituições, principalmente as de saúde, educação, bem-estar social e cultura, operam como elementos que reproduzem e aprofundam as condiç̃̃es sociais de vulnerabilidade. ${ }^{18}$

\section{Classe 5 - Formas de relação consigo e com o mundo: descortinando modos de enfrentamento da AIDS}

Esta classe representa $31,84 \%$ das UCE analisadas. As palavras lexicais que mais expressam esta classe são pesso $+\left(x^{2}\right.$ $59,57)$, vid $+\left(x^{2} 45,12\right)$, doença $+\left(x^{2} 42,21\right)$, normal $+\left(x^{2} 33,34\right)$, filhos ( $\left.x^{2} 28,12\right)$, tivess $+\left(x^{2} 25,77\right)$, import+ ( $\left.x^{2} 21\right)$, ach $+\left(x^{2}\right.$ $17,57)$, explic $+\left(x^{2} 17,44\right)$, frente $\left(x^{2} 15,82\right)$, portador $+\left(x^{2} 15,71\right)$, assunto + ( $\left.x^{2} 15,07\right)$, conviv+ ( $\left.x^{2} 14,25\right)$, entend $+\left(x^{2} 14,22\right)$, pen+ $\left(x^{2} 13,59\right)$ e aceit+ $\left(x^{2} 12,91\right)$. Nesta classe os sujeitos referem-se às formas de enfrentamento diante da doença e seus modos de encarar a vida, após o diagnóstico. 
A principal forma de enfrentamento é a negação da doença, que se expressa na falta de mudança do cotidiano e caracteriza a vida como normal. Diante desse contexto, nota-se um aspecto negativo no que se refere a esta normalização, podendo levar à indiferença e à falta de interesse em buscar informação acerca da doença por parte do portador do vírus, e consequentemente, prejudicar o autocuidado e o cuidado do outro. Isso também possibilita a continuidade de práticas que podem aumentar a chance de disseminação do HIV.

Eu vi que tinha que encarar de frente, então, até hoje eu encaro, eu vivo como se nada tivesse acontecido, eu vivo uma vida normal, não sei da precaução que a gente tem que tomar, eu sei que é importante estar tomando as medicações, eu acho que é isso (E 2).

Percebe-se ainda, na discursividade dos sujeitos deste estudo, certa incerteza diante de algumas informações concernentes à doença, tais como as formas de proteção. Este se torna um dado preocupante, já que pode acarretar, em especial, a disseminação da doença. 0 fato de os sujeitos entenderem a terapia medicamentosa como importante no tratamento da doença pode indicar uma deficiência na implementação de um cuidado mais integral à pessoa que vive com HIV/AIDS, que se foca na medicalização, esquecendo-se das demais demandas trazidas com a doença, as quais também precisam ser abordadas, de forma não menos importante.

Faz-se necessário, neste sentido, lançar um olhar que transcenda o conceito de doença como um fato meramente biológico, para entendê-la como vinculada, também, à cultura, ou seja, como um estado transitório ou permanente sentido pela pessoa que se encontra localizado no ínterim entre o biológico e o cultural. ${ }^{14}$

Apesar da tentativa de naturalização da doença no cotidiano, alguns sujeitos reconhecem que a vida normal não é algo alcançável devido, sobretudo, ao preconceito relacionado à AIDS, o qual se traduz na rejeição por parte das pessoas que estão à sua volta. Junto com o preconceito também está o medo diante da doença, configurando-se em conflitos no relacionamento interpessoal.

Horrivel, vocênão tem uma vida normal, parece até que todo mundo te rejeita. Mas não ébem assim, então as pessoas rejeitam, eu percebo. A gente percebe, entendeu? E depois a gente vaise acostumando, vaise acostumando (E 11).

Pra mim, a AIDS infelizmente, é uma doença que traz muito preconceito, as pessoas são muito preconceituosas com aAIDS e traz um pouco de medo, então a AIDS para mim traz muito problema, especialmente no contato comas pessoas (E8).

Um aspecto constituinte da representação social da AIDS, comportando uma atitude negativa, refere-se à morte, fortemente atrelada à doença. Esta representação influencia a adesão à terapia medicamentosa, já que os sujeitos não veem sentido em sua realização, pois a morte é considerada inevitável para as pessoas que vivem com o HIV. Um dos sentimentos ligado à AIDS que pode revelar uma dimensão afetiva presente nas representações sociais da doença foi o de pena diante do adoecimento de alguém conhecido, que traz, ainda, a conotação de morte precoce.

[...] pra pessoa que acha que não vale mais a pena viver, que acha que não vale mais a pena fazer 0 tratamento, porque ela acha que vai morrer de qualquer jeito mesmo, entende (E 13).

Pena porque eu achava que ele poderia vivermais (E6).

Neste sentido, destaca-se que os soropositivos que conseguiram concretizar o processo de adesão tiveram uma vida mais prolongada, tendo que, ao mesmo tempo, reaprender a viver, considerada fundamental a participação do próprio indivíduo como um sujeito ativo neste processo. Apesar de AIDS não ter cura, existem outras atitudes para o seu enfrentamento, como a cura paliativa, 0 pensamento positivo e a vida saudável. ${ }^{5}$

A AIDS encontra-se ancorada em certas doenças que foram traduzidas como pragas (pestes) e câncer. No que se refere à expressão "pragas do Egito", nota-se a percepção da AIDS como punição divina, cujo sentido maior é conscientizar alguém de alguma coisa, com um objetivo prático, principalmente de ressignificação da vida.

Destruição mesmo, tipo as pragas do Egito, entende? Bem... bemnesse patamar mesmo, eu entendo isso como um castigo, como uma forma de parar as pessoas para que elas se conscientizem da gravidade da vida, de você valorizar a vida e saber viver e não brincar com ela [...] e não tem a dificuldade de entender uma pessoa que está com câncer (E 13).

Além disso, a AIDS tem sido considerada por alguns sujeitos como uma doença crônica, comparada com a hipertensão arterial e o diabetes. Essa cronicidade da doença contribui para o enfrentamento da doença e para o aumento da perspectiva de vida das pessoas que convivem com o HIV.

Não se trataram. Podiam ter prolongado mais a vida porque hoje tem como né? (E 6).

Eu não sinto nada, foi mais um recado, mais uma doença. Se eu não tivesse hipertensão e nem diabetes, eu não teria essa cabeça eu acho, entendeu. Por já me conformar com suas crônicas, a terceira não me abalou (E 7).

Em relação à adesão medicamentosa, nota-se uma dificuldade em realizá-la, ao mesmo tempo em que os sujeitos 
expressam a importância dela para sobreviver e viver com a doença, podendo alcançar o que se considera uma vida normal desejada.

Fulano não adere por conta disso [...] entende a atitude que ela toma, erradamente, mas ela toma, mesmo sabendo que ela tem, porque de agora em diante ela depende daquilo para viver (E 13).

Ele pode ter uma vida normal, normal desde o momento que ele se trate, tome as medicações direito, né?(E 2).

Outro tipo de enfrentamento da doença é o ocultamento em relação ao diagnóstico, principalmente para a família, a falta de interesse por buscar informações, a ressignificação e valorização da vida, buscando um sentido para esta, que se expressa principalmente pela busca da espiritualidade, e a busca de apoio psicológico e espiritual, além do apoio por entes queridos, que elevam a autoestima do portador do vírus. Nota-se que os sujeitos justificam a omissão da sua condição soropositiva como uma forma de autoproteção.

Nem penso, nem procuro saber, eu não gosto de ficarlembrando sabe? (E 1).

Foi complicado no meio da familia, porque a família interpreta como realmente foi, uma traição, entende? Um desrespeito (E 13).

Que ali ele venha ter todo o tratamento, até psicológico, porque muitos tentam o suicídio e precisam de apoio ( $E$ 8).

Observou-se, em um estudo ${ }^{7}$, que os adolescentes soropositivos guardam em segredo o seu statussorológico, uma vez que o medo da rejeição resulta em um afugentamento do convívio social. Neste caso, o fato de não revelarem a sua sorologia pode gerar uma segregação social. Entretanto, algumas pessoas preferem se relacionar com outras que possuem a mesma condição sorológica, o que se constitui como uma estratégia de enfrentamento e apoio mútuo. Isso possibilita trocas de experiências diante da síndrome, além de não ter que se submeter ao preconceito advindo das pessoas ditas normais.

Destaca-se que a espiritualidade se apresenta como uma dimensão muito presente no cotidiano das pessoas que vivem com o HIV, indo além de uma forma de enfrentamento, de apoio e de ver e viver a vida, mas sendo também uma possibilidade de cura, a partir da crença e fé no divino, mesmo para uma doença incurável.

Porque não tem ninguém para ouvir, só eu e Deus, posso contar meus segredos, apesar de que Deus sabe todos. (E 8).
Porque fazer milagre é o que Deus sabe fazer, entendeu? Não que Deus não saiba curar, claro, Deus sabe fazer tudo, Deus pode fazer tudo, mas uma das coisas que eles faz se você tiver fé, é curar, independente se você está morto, se você estiver morrendo (E 13).

Observa-se que a relação com o divino se estabelece em diversas dimensões, desde a de confidente de uma situação que deve ser escondida, inclusive de pessoas próximas (o que fornece a ideia de confiança que se tem neste ser), até a possibilidade de cura física. Estas dimensões parecem se complementar, fornecendo sentido ao cotidiano dos indivíduos, assim como dotando-os de esperança de resolverem uma situação que, atualmente, à luz da ciência médica é impossível.

Apesar das limitações da ciência, no cotidiano assistencial dos profissionais de saúde, parece imprescindível serem levadas em conta as dimensões e vulnerabilidades espirituais das pessoas que vivem com HIV e AIDS, de forma a conferir maior aproximação às demandas subjetivas destas pessoas e contribuindo, assim, para maior integralidade da assistência. ${ }^{10}$

\section{CONCLUSÕES}

Conclui-se que este trabalho revela dimensões afetivas e comportamentais dos pacientes presentes nas relações que estabelecem e nas representações sociais acerca da AIDS.

Observa-se que os conteúdos representacionais dos sujeitos apresentam-se de maneira peculiar, por vezes tensa e conflituosa e, por outras, de maneira positivamente afetiva e esperançosa.

Pode-se verificar que o cotidiano dos pacientes é marcado por um campo repleto de tensões, no qual éfundamental a reflexão acerca da coexistência ou inexistência de preconceitos por parte dos profissionais de enfermagem e do aumento das necessidades psicoafetivas e da sensibilidade de pacientes portadores de HIV/ AIDS. Norteando esta reflexão, aponta-se que, apesar de terem sido identificadas, no discurso de alguns sujeitos, atitudes preconceituosas no cuidado de enfermagem voltado para o HIV/AIDS, a possibilidade de vínculo, de amizade e de cuidado humanizado também faz parte do cotidiano dos sujeitos de forma intensa.

Nota-se que a representação social da AIDS associada à prevenção ou à disseminação do HIV está, respectivamente, na utilização ou não de preservativos. A atitude diante da terapia com antirretrovirais é positiva, visto que é percebida como uma possibilidade de prolongamento da vida. Destaca-se, também, que o modo de enfrentamento da doença mais freqüente no grupo estudado é a negação e a busca de outras redes de apoio.

Sob a perspectiva teórica das representações sociais, este estudo trouxe à tona o caráter interativo no processo de construção das representações. Estas últimas, por seu turno, retroalimentam o modo como as relações são estabelecidas e mantidas entre a pessoa soropositiva consigo mesma, com profissionais de saúde e com a sociedade como um todo. Parece claro que os sujeitos 


\section{As facetas do convívio com HIV/AIDS}

soropositivos entrevistados esquematizam suas relações interpessoais e consigo a partir de uma organização psicossociológica da AIDS. Esta organização, por vezes, se mostra influenciável pela comunicação social mediada por veículos de comunicação. Neste sentido, apesar da influência da dimensão individual nestas relações interpessoais, elas são assumidas enquanto fruto dos intercâmbios sociais e pertencentes à vida coletiva, vivida ativamente sob diversos contextos, seja sob o cuidado de enfermagem, no ambiente familiar, na condição de cidadão e no dia-a-dia de indivíduo com status sorológico positivo para o HIV.

0 presente estudo apresenta como itens a serem considerados, no que tange às limitações que o caracterizam, 0 pequeno número de sujeitos, uma vez que se refere a resultados preliminares da pesquisa desenvolvida; e a discursividade produzida no ambiente hospitalar que se, por um lado, expõe a subjetividade permeada por este ambiente, por outro, pode estar impregnada de emoções negativas em função do sofrimento que caracteriza esta situação. Além disso, o aprofundamento vertical propiciado pelo software não permite a compreensão de maneira mais integral de determinadas questões, para a qual seria necessária a utilização de outros recursos informatizados do próprio ALCESTE ou a realização de análises manuais.

Quanto às implicações dos resultados obtidos para o cuidado de enfermagem, apreender a forma com a qual as pessoas que vivem com HIV/AIDS se relacionam, constroem e legitimam seus modos de ser-no-mundo, significa obter - da maneira mais direta - os subsídios necessários a uma prática assistencial mais humanista, centrada na pessoa soropositiva enquanto ser social, que possui um conjunto de saberes e de práticas normalmente tolhidos a partir das construções simbólicas da AIDS. Em outras palavras, por meio do olhar das representações sociais elaboradas pelos pacientes soropositivos sob o seu cuidado, o enfermeiro dispõe de recursos tão ou mais sofisticados do que aqueles de natureza tecnológica para a concretização de formas alternativas de cuidado, que perpassem tanto a sua dimensão biomédica quanto relacional/humanística. Este aparato de fatores coaduna-se ao ideário de um cuidado melhor, qual seja, aquele que se revisita e se remodela, pautado no diálogo, no amor e na liberdade.

\section{REFERÊNCIAS}

1. Jodelet $D$. Representações sociais: um domínio em expansão. In: Jodelet D, organizadora. As representações sociais. Rio de Janeiro: Eduerj; 2001. p.17-44.

2. Castilho EA, Chequer P. Epidemiologia do HIV/Aids no Brasil. In: Parker R, organizador. Políticas, instituições e AIDS: enfrentando a epidemia no Brasil. Rio de Janeiro: J Zahar; 1997. p.17-44.

3. Galvão J. 1980-2001: uma cronologia da epidemia de HIV/AIDS no Brasil e no mundo. Rio de Janeiro: ABIA; 2002.

4. BarbaráA, Sachetti VAR, Crepaldi MA. Contribuições das representações sociais ao estudo da AIDS. Interação em Psicologia. 2005 jul/dez; (9)2: 331-9.
5. Costa JP, Silva LMS, Silva MRF, Miranda KCL. Expectativas de pacientes com HIV/AIDS. Rev Bras Enferm. 2006 mar/abr; 59(2): 172-76.

6. Paula CC, Crossetti MGO. A existencialidade da criança que convive com AIDS. Esc Anna Nery. 2008 mar; 12(1): 30-8.

7. Thiengo MA, Oliveira DC, Rodrigues BMRD. Representações sociais do HIV/AIDS entre adolescentes: implicaç̃̃es para os cuidados de enfermagem. Rev Esc Enferm USP. 2005 mar; 39(1): 68-76.

8. Schaurich D, Coelho DF, Motta MGC. A cronicidade no processo saúdedoença: repensando a epidemia da AIDS após os anti-retrovirais. Rev Enferm UERJ. 2006 jul/set; 14(3): 455-62.

9. Cardoso GP, Arruda A. As representações sociais da soropositividade e sua relação com a observância terapêutica. Cienc Saude Colet. 2005 jan/ mar; 10(1): 151-62.

10. Santos Él, Gomes AMT, Oliveira DC, Santo CCE, Felipe ICV, Lima RS. The principle of comprehension in HIV/AIDS context: an integrative review. Rev Pesq Cuid Fundam Online [periódico on-line]. 2010 out/dez; [citado 2010 dez 01]; 2(4): [aprox. 11 telas]. Disponível em: http:// www.seer.unirio.br/index.php/cuidadofundamental/article/view/1290.

11. Abric JC. A zona muda das representações sociais. In: Oliveira DC, Campos PHF, organizadores. Representações sociais: uma teoria sem fronteiras. Rio de Janeiro: Museu da República; 2005. p. 27-38.

12. Oliveira DC, Gomes AMT, Marques SC. Análise estatística de dados textuais na pesquisa das representações sociais: alguns princípios e uma aplicação ao campo da saúde. In: Menin MSS, Shimizu AM, organizadores. Experiência e representação social: questões teóricas e metodológicas. São Paulo: Casa do Psicólogo; 2005. p. 157-200.

13. Grüdtner DI, Carraro TE, Sobrinho SH, Carvalho ALG, Campregher G. 0 amor no cuidado de enfermagem. Rev Enferm UERJ. 2010 abr/jun; 18(2): 317-22.

14. Leite JL, Erdmann AL, Carvalho SM, Pezzi MCS, Dantas CC. 0 caminhar para a concepção de um modelo de cuidado. Cienc Cuid Saude. 2007 abr/ jun; 6(2): 187-96.

15. Teixeira ER. 0 ético e o estético nas relações de cuidado em enfermagem. Texto\& Contexto Enferm. 2005 mar; 14(1): 89-95.

16. Oltramari LC, Otto LS. Conjugalidade e AIDS: um estudo sobre infecção entre casais. Pscicol Soc. 2006 set/dez; 18(3): 55-61.

17. Herzlich C, Pierret J. Uma doença no espaço público. A AIDS em seis jornais franceses. Phyisis 2005; 15(supl): 71-101.

18. Ayres JRCM, Calazans GJ, Saletti Filho HC, França-Júnior I. Risco, vulnerabilidade e práticas de prevenção e promoção da saúde. In: Campos GWS, Minayo MCS, Akerman M, Drumond Júnior M, Carvalho YM, organizadores. Tratado de saúde coletiva. São Paulo: Hucitec; 2006. p. $375-417$

Recebido em 15/12/2010 Reapresentado em 05/08/2011 Aprovado em 05/10/2011 